\title{
Estimation of Crop and Forest Areas using Expert System based Knowledge Classifier Approach for Aurangabad District
}

\author{
Sandip S. Thorat, Yogesh. D. Rajendra, K. V. Kale, S. C. Mehrotra \\ Department of Computer Science \& Information Technology, \\ Dr. Babasaheb Ambedkar Marathwada University, Aurangabad, (MS). India
}

\begin{abstract}
The present study demonstrates the application of remote sensing for the estimation of areas corresponding to crop and forest lands covered in the district of Aurangabad, (Maharashtra), India. The data acquired by IRS-P6 Advanced Wide Field Sensors (AWiFS) having 56m spatial resolution for the months of October \& December 2012 which covered complete study areas with its swath of $740 \mathrm{Km}$ has been used for the study. The Maximum Likelihood Classification (MLC) and Knowledge Classification (KC) techniques based on Decision Tree approach were applied. It has basically two elements, knowledge engineering and knowledge classifier. Knowledge engineering provides an interface to build up decision tree which defines the rules and variables represented by three parameters, i.e. Normalized Difference Vegetation Index (NDVI), Soil Adjust Vegetation Index (SAVI), and Normalized Difference Water Index (NDWI) threshold value of each class. Knowledge classifier generates the required output classification. The objective of this research work is to perform classification of crop and forest acreage estimation from the AWiFS data and comparing it to the supervised classification techniques, MLC and KC. The result shows that values of overall classification accuracy were $82 \%$ and $84 \%$ for the months of December and October 2012 respectively using MLC, whereas corresponding values of accuracy were found to be $85 \%$ and $87 \%$ based on KC. Thus the classification results based on KC provide better results than corresponding results based on the MLC.
\end{abstract}

\section{Keywords}

IRS-P6 Advanced Wide Field Sensors, Knowledge Classification, Maximum Likelihood Classification, Crop, Forest, Accuracy Assessment.

\section{INTRODUCTION}

Classification of Crop and Forest land cover is very important in national and regional planning. Because of the increase in population and global climate change, the field of remote sensing for monitoring and estimation has gained more importance. The technology provides broad coverage with reasonable accurate information of ground data. The estimation of crop area is of particularly importance in regional area like Aurangabad, because crops provide economical and social sustainability, whereas forest provides natural resources and helps to maintain the atmospheric balance $[1,2]$. The cropping pattern in this region has two growth seasons per year, i.e. Kharif and Rabi. Ithese Crops are harvested in the months of November and January. The yield of Crops along with estimation of forest in many places are based on conventional methods of field based data collection for crop and yield estimation based on groundbased field reports. These methods are expensive, time consuming and also prone to large errors due to imperfect ground observations, leading to poor assessment and area estimations. In many cases availability of such data gets too late to take appropriate actions. Remote sensing offers efficient and reliable means to map crop \& forest areas [3, 4].

In this study supervised classification approach were used for image analysis on remote sensed data. In this approach the image pixel are classified to various predefined land use land cover classes based on the spectral reflectance value at a different band at the time. Due to similar values of reflectance of many similar crops, there is likely to be spectral confusion. So it is very difficult to solve problem of spectral confusion using traditional parametric classifier like maximum likelihood [5]. With the help of Knowledge Classifier we can reduce this confusion using extra knowledge gathered from ancillary data or other data such as DEM, Toposheet vegetation map [6]. Due to this fact knowledge classification is preferable.

\section{STUDY AREA}

Our study area is chosen to be Aurangabad District in the state of Maharashtra, India. It is located between Latitude 74 and 76 degrees east and Longitude 19 and 20 degrees North having the area covering approximately $10,100 \mathrm{~km}^{2}$, Out of which $141.1 \mathrm{~km}^{2}$ is urban area and $9,958.9 \mathrm{~km}^{2}$ is rural. Aurangabad District is Located mainly on Godavari River and surrounded by Purna, Shivna, Maniyad, and Kham which are major rivers. The climate has 3 distinct seasons. The rainy season is normally from the months of June to September. The winter is from the month of October to February and the summer from March to May. The average rainfall of Aurangabad is about $734 \mathrm{~mm}$ and the temperature is the range of 5-47 degrees Celsius. The District has major kharif season (Period from the month June to December). The major crop during the Khariff season are cotton, sugarcane maize, Bajra groundnut. Apart from vegetation and forest land, the sanctuary area (Gautala Autramghat) is a protected area of Maharashtra state, India. It lies in the Satmala and Ajantha hill ranges of the Western Ghats. The wildlife sanctuary was established in 1986 in the existing reserved forest area [7, 8].

\section{METHODOLOGY}

The atmospheric corrected AWiFS data were selected having the 1:50,000 georeferenced scale. Extraction of area of interest (AOI) from the image has been carried out. Seven training samples for land use land cover classes viz. Water, Settlement, Forest, Shrubs, Crop, fallow Land, and Barren 
Land have been done. The Figure 1 shows the overall classification activity diagram, which we have performed on extracted images of Aurangabad region from the satellite image.

The ERDAS Software was used for image processing and analysis to carry out the data processing. The training sites of each class in AOI were used for generating the spectral signature and also for the calculation of the vegetation indices. The indices were calculated for each class specifically and getting threshold values in the minimum and maximum range as input to the knowledge engineer interface for formulation (building) of decision tree.

The AWiFS images are georeferenced with the second order polynomial distribution. The WGS-84 coordinate system was used for the Lambert Conic Conformal Projection [9]. Ground truth data was collected via field trips of AOI and gathered information such as Crop Sowing date, water delivery status, amount of fertilizers required and crop Health [5] from concerned persons(farmers). Accordingly fieldwork was undertaken covering kharif crop seasons. A total of 90 ground truth points were collected. The coordinates of the ground truth points were recorded with the help of handheld Mobile $[10,8]$.

The three vegetation indices were generated, namely Normalize Difference Vegetation Index (NDVI), Normalized Difference Water Index (NDWI) and Soil Adjust Vegetation Index (SAVI) from the AWiFS imagery. These Indices provide useful vegetation information about the given land. The soil background condition is very important for a vegetation change due to this purpose appropriate. The remote sensing based algorithm was applied. Also it can be used to characterize the proportion of area covered by the crop [11, 2].

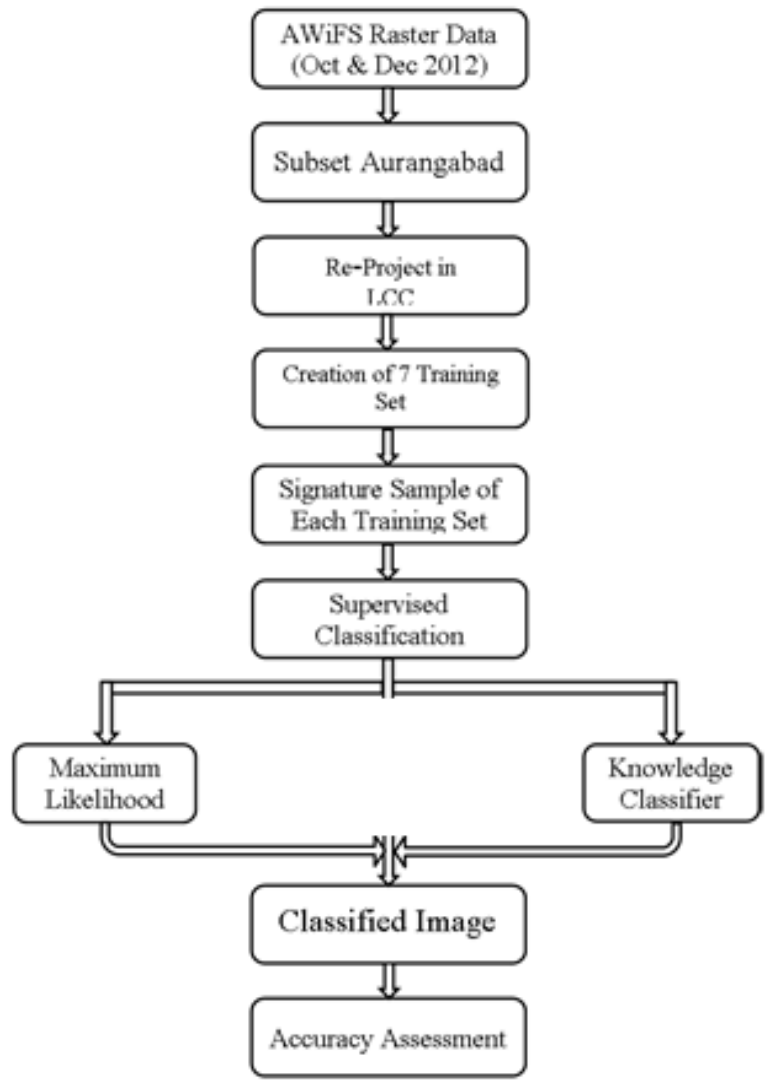

Fig 1: Flowchart of Classification Scheme

\section{EXPERIMENTAL ANALYSIS}

Table 1. The NDVI threshold values in each class for October-2012 Dataset

\begin{tabular}{|c|c|c|}
\hline Class & Minimum & Maximum \\
\hline Water & -0.21 & 0.22 \\
\hline Settlement & 0.02 & 0.18 \\
\hline Forest & 0.33 & 0.55 \\
\hline Barren Land & 0.07 & 0.36 \\
\hline Shrubs & 0.14 & 0.31 \\
\hline Crop & 0.36 & 0.65 \\
\hline Fallow Land & 0.43 & 0.36 \\
\hline
\end{tabular}

Table 2. The NDVI threshold values in each class for December-2012 Dataset

\begin{tabular}{|c|c|c|}
\hline Class & Minimum & Maximum \\
\hline Water & -0.36 & 0.17 \\
\hline Settlement & 0.03 & 0.19 \\
\hline Forest & 0.09 & 0.37 \\
\hline Barren Land & 0.07 & 0.19 \\
\hline Shrubs & 0.08 & 0.26 \\
\hline Crop & 0.26 & 0.63 \\
\hline Fallow Land & 0.08 & 0.33 \\
\hline
\end{tabular}

Table 3. Class wise Area cover by using Knowledge Classifier

\begin{tabular}{|c|c|c|c|}
\hline \multicolumn{2}{|c|}{ October-2012 } & \multicolumn{2}{c|}{ December-2012 } \\
\hline Class & Area in ha. & Class & Area in ha. \\
\hline Water & 9608.10 & Water & 9370.36 \\
\hline Settlement & 5862.75 & Settlement & 5958.92 \\
\hline Forest & $26,686.7$ & Forest & 26,624 \\
\hline Barren Land & 10,160 & Barren & 15221 \\
\hline Shrubs & $1,54,346$ & Shrubs & 127430 \\
\hline Crop & $4,85,463$ & Crop & $3,28,404$ \\
\hline Fallow Land & $2,86,995$ & Fallow & $4,63,045$ \\
\hline \multicolumn{4}{|c|}{} \\
\hline
\end{tabular}

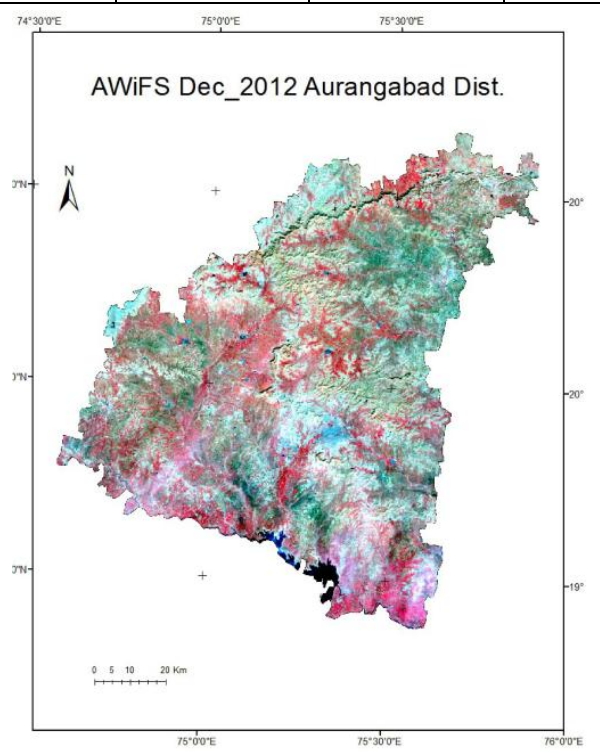

Fig 2: FCC Image of Aurangabad District 


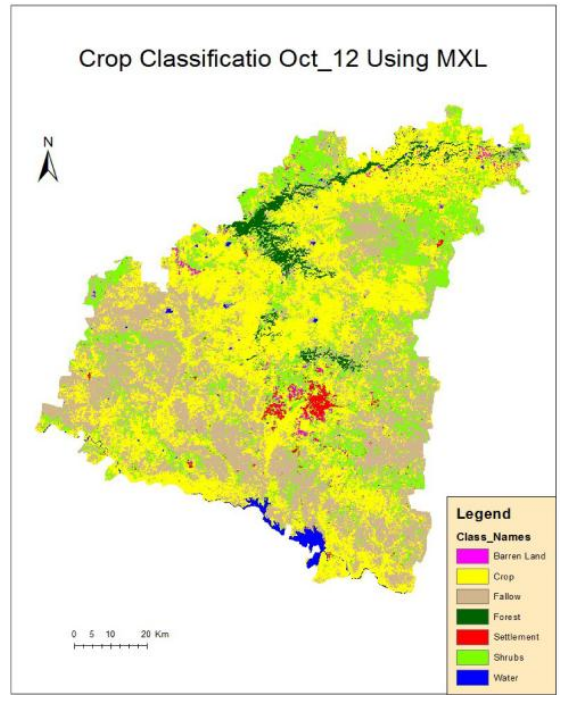

Fig 3: Classified Image Oct-2012 using MXL

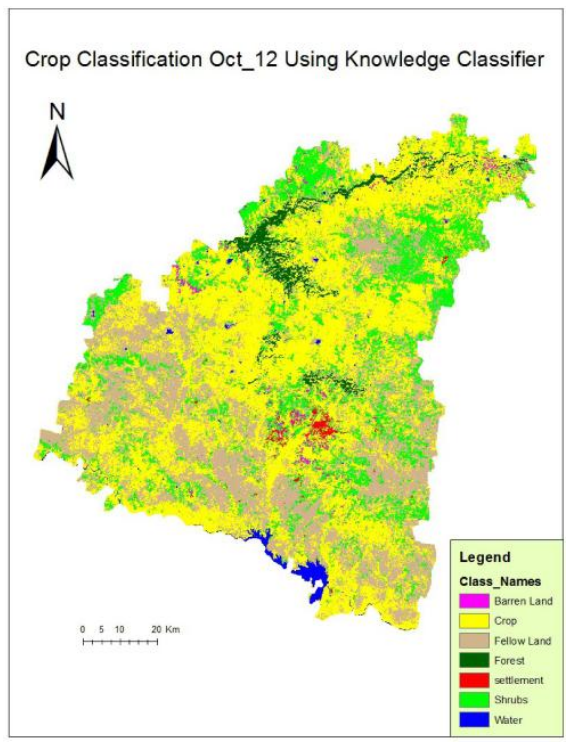

Fig 4: Classified Image Oct-2012 using Knowledge Classifier

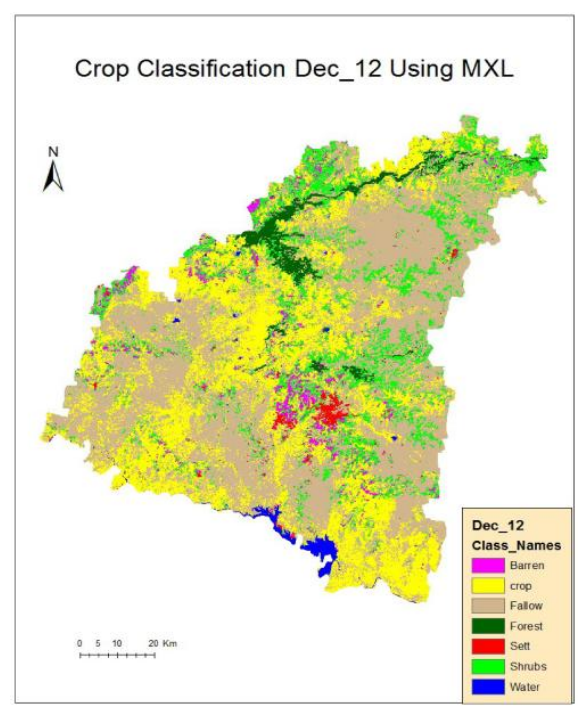

Fig 5: Classified Image Dec-2012 by using MXL

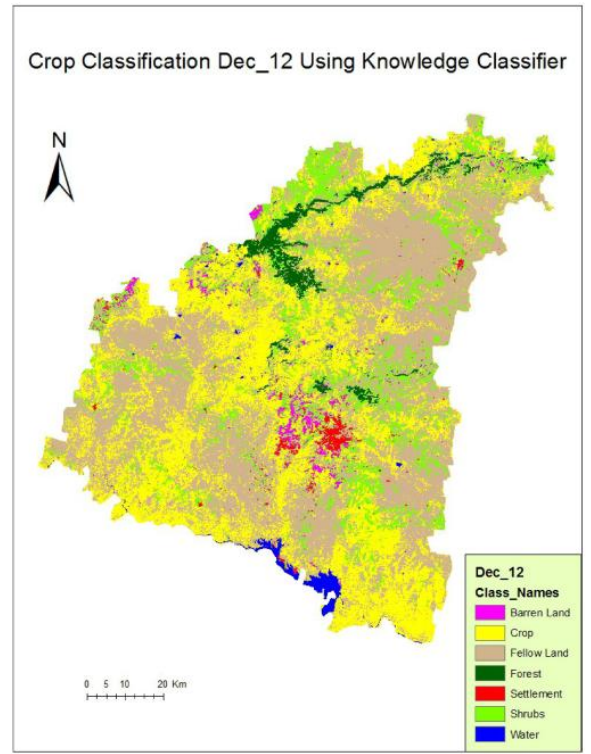

Fig 6: Classified Image Dec-2012 By using Knowledge Classifier

The Figure 2 shows the FCC image of study area. The Figures 3-6 show classified images using Supervised MLC and KC. The Tables 1 and 2 show NDVI threshold values for each class which are used for making Decision tree in Knowledge engineer interface. The Table 3 gives values of areas for Crops and Forest cover in Aurangabad region using KC. The Result shows total area covered for the seven classes separately in hector. The crop area covered in the month of October is $485463 \mathrm{Ha}$, and in the month of December was $328404 \mathrm{Ha}$. The Difference shows that there is $15,70,59 \mathrm{Ha}$ Crop area harvested and that has been converted to fallow land. The result shows that fallow land gets increased in the months of October and December by $26,686.7 \mathrm{Ha}$ and $26,624 \mathrm{Ha}$ respectively.

\section{ACCURACY ASSESMENT}

To validate the classification accuracy, the stratified random sampling method were used to collect sample data on the field. The equal numbers of sample points ware selected to each strata. Using these field data, the confusion and error matrices were determined and given in Tables 4 and 5, respectively. One can estimate accuracy through confusion matrix or error matrix in terms of Producer's accuracy, User's accuracy and overall accuracy with Kappa coefficient (K).

Table 4. Confusion Matrix of Accuracy Assessment Oct$2012(\mathrm{KC})$

\begin{tabular}{llllll}
\hline $\begin{array}{l}\text { Class } \\
\text { Name }\end{array}$ & $\begin{array}{l}\text { Ref } \\
\text { Tot }\end{array}$ & $\begin{array}{l}\text { Class } \\
\text { Tot }\end{array}$ & $\begin{array}{l}\text { Num } \\
\text { Corr }\end{array}$ & $\begin{array}{c}\text { Prod } \\
\text { Acc }\end{array}$ & $\begin{array}{l}\text { Users } \\
\text { Acc }\end{array}$ \\
\hline Shrub & 18 & 15 & 12 & $66.67 \%$ & $80.00 \%$ \\
\hline Crop & 38 & 41 & 35 & $92.11 \%$ & $85.37 \%$ \\
\hline Settle & 11 & 10 & 10 & $90.91 \%$ & $100.00 \%$ \\
\hline Forest & 10 & 10 & 10 & $100.00 \%$ & $100.00 \%$ \\
\hline Fallow & 17 & 13 & 12 & $70.59 \%$ & $92.31 \%$ \\
\hline Water & 11 & 11 & 11 & $100.00 \%$ & $100.00 \%$ \\
\hline Barren & 15 & 20 & 13 & $86.67 \%$ & $65.00 \%$ \\
\hline Totals & $\mathbf{1 2 0}$ & $\mathbf{1 2 0}$ & $\mathbf{1 0 3}$ & & \\
\hline
\end{tabular}

Overall Classification Accuracy $=\mathbf{8 5 . 8 3 \%}, \mathbf{K}=\mathbf{0 . 8 0}$ 
Table 5. Confusion Matrix of Accuracy Assessment Dec2012(KC)

\begin{tabular}{llllll}
\hline $\begin{array}{l}\text { Class } \\
\text { Name }\end{array}$ & $\begin{array}{l}\text { Ref } \\
\text { Tot }\end{array}$ & $\begin{array}{l}\text { Class } \\
\text { Tot }\end{array}$ & $\begin{array}{l}\text { Num } \\
\text { Corr }\end{array}$ & $\begin{array}{l}\text { Prod } \\
\text { Acc }\end{array}$ & $\begin{array}{l}\text { User } \\
\text { Acc }\end{array}$ \\
\hline Fallow & 18 & 15 & 14 & $77.78 \%$ & $93.33 \%$ \\
\hline Crop & 53 & 58 & 51 & $96.23 \%$ & $87.93 \%$ \\
\hline Settle & 2 & 2 & 2 & $100.00 \%$ & $100.00 \%$ \\
\hline Shrubs & 21 & 24 & 20 & $95.24 \%$ & $83.33 \%$ \\
\hline Barren & 14 & 14 & 12 & $85.71 \%$ & $85.71 \%$ \\
\hline Forest & 7 & 2 & 1 & $14.29 \%$ & $50.00 \%$ \\
\hline Water & 5 & 5 & 5 & $100.00 \%$ & $100.00 \%$ \\
\hline Totals & $\mathbf{1 2 0}$ & $\mathbf{1 2 0}$ & $\mathbf{1 0 5}$ \\
\hline Overall Classification Accuracy $=$ & $\mathbf{8 7 . 5 0 \%}, \mathbf{K = 0 . 8 2}$
\end{tabular}

\section{CONCLUSIONS}

In this study we have estimated actual area covered by the Crop and Forest from the AWiFS imagery, and we found that the results were very satisfactory. After comparing the results achieved by the maximum likelihood and Knowledge classifier it is demonstrated that knowledge classifier is more suitable for temporal images for finding the Vegetation Cover. The overall accuracies of system using Maximum Likelihood approach were $82 \%$ and $84 \%$ for the months of October and December respectively. The corresponding accuracies by Knowledge classifier were found to be $85.83 \%$ and $87.50 \%$. It is concluded that the Knowledge Classifier is more reliable and satisfactory for classifications of Crops and Forest using the remote sensing data.

\section{ACKNOWLEDGMENTS}

Authors would like to acknowledge the University Grants Commission (UGC), India for granting UGC SAP (II) DRS Phase-I \&Phase-II F. No. 3-42/2009 \& 4-15/2015/DRS-II Biometrics: Multimodal System Development Laboratory facility and One Time Research Grant F. No. 4-10/2010 (BSR)\& 19-132/2014 (BSR). We also thanks DST-FIST programme for research assistance supporting the work at Department of Computer Science and Information Technology, Dr. Babasaheb Ambedkar Marathwada University, Aurangabad, Maharashtra, India. The assistance from the Ramanujan Geospatial chair is also appreciated.

\section{REFERENCES}

[1] Qinghan, D., Herman, E., \& Zhongxin, C. 2008. Crop area assessment using remote sensing on the North China Plain. The International Archives of the Photogrammetry, Remote Sensing and Spatial Information Sciences, 37, 957-962.
[2] Karthikeyan, N., Shashikkumar, M. C., \& Ramanamurthy, J. 2010. A study on vegetation vigour as affected by soil properties using remote sensing approach. In Recent Advances in Space Technology Services and Climate Change (RSTSCC), 2010 (pp. 107110). IEEE.

[3] Singh, P. P., Garg, R. D., \& Raju, P. L. N. 2013. Classification of high resolution satellite imagery: an expert system based approach. In Proceedings of 34th Asian Conference on Remote Sensing (pp. 20-24).

[4] Taweesuk, S., \& Thammapala, P. 2005. Expert classification technique for mapping teak plantation areas in Thailand.

[5] Jia, K., Wei, X., Gu, X., Yao, Y., Xie, X., \& Li, B. 2014. Land cover classification using landsat 8 operational land imager data in Beijing, China. Geocarto International, 29(8), 941-951.

[6] Bharti, A. 2004. A Decision Tree Approach to Extract Knowledge for Improving Satellite Image Classification (Doctoral dissertation, Ph. D. Thesis, International Institute for Geo-information Science and Earth Observation)

[7] Pooja, A. P., Jayanth, J., \& Koliwad, S. 2011 Classification of RS data using decision tree approach. algorithms, 1(10), 3

[8] Panigrahy, R. K., Ray, S. S., \& Panigrahy, S. 2009. Study on the utility of IRS-P6 AWIFS SWIR band for crop discrimination and classification. Journal of the Indian Society of Remote Sensing, 37(2), 325-333.

[9] Singh, P. P., Garg, R. D., \& Raju, P. L. N. 2013. Classification of high resolution satellite imagery: an expert system based approach. In Proceedings of 34th Asian Conference on Remote Sensing (pp. 20-24).

[10] Singh, N. J., Kudrat, M., Jain, K., \& Pandey, K. 2011. Cropping pattern of Uttar Pradesh using IRS-P6 (AWiFS) data. International journal of remote sensing, 32(16), 4511-4526.

[11] Cohen, Y., \& Shoshany, M. 2000. Integration of remote sensing, GIS and expert knowledge in national knowledge-based crop recognition in Mediterranean environment. International archives of photogrammetry and remote sensing, 33(B7/1; PART 7), 280-286. 